Simposium I Jaringan Perguruan Tinggi untuk Pembangunan Infrastruktur Indonesia, 2016

\title{
Konstruksi Ulang Kebijakan Fasilitas Bea Masuk Untuk Meningkatkan Produktivitas Industri Galangan Kapal di Indonesia
}

\author{
Edi Slamet Irianto ${ }^{\mathrm{a}, \mathrm{b}}$, Haula Rosdiana $^{\mathrm{a}, \mathrm{b} *}$, Sunaryo $^{\mathrm{c}}$, Maria RUD Tambunan $^{\mathrm{a}, \mathrm{b}}$, Inayati $^{\mathrm{a}, \mathrm{b}}$ \\ ${ }^{a}$ Fakultas Ilmu Administrasi Universitas Indonesia, Gedung B Lantai 2 Kampus FISIP UI, Depok 16424 \\ ${ }^{b}$ Kluster Politik Perpajakan, Kesejahteraan dan Ketahanan Negara, Gedung B Lantai 2 Kampus FISIP UI, Depok 16424 \\ ${ }^{c}$ Teknik Perkapalan, Fakultas Teknik Universitas Indonesia, Depok 16424
}

\begin{abstract}
Abstrak
Industri galangan kapal merupakan salah satu pilar penting dalam mewujudkan Indonesia sebagai poros maritim dunia, karena itu kebijakan insentif pajak sebagai pull factor harus didisain dengan baik agar efisien dan efektif. Salah satu insentif pajak yang diberikan pemerintah untuk mendorong daya saing industri galangan kapal adalah Bea Masuk Ditanggung Pemerintah (BMDTP). Dalam praktiknya, tidak banyak pelaku usaha yang memanfaatkan fasilitas BMDTP. Berdasarkan hasil analisis atas pengumpulan data dengan menggunakan studi literatur, studi dokumentasi dan field research berupa Focused Group Discussion, disimpulkan bahwa BMDTP yang lebih cocok sebagai spending policy dibanding sebagai tax policy, tidak sesuai dengan nature of business industri galangan kapal di Indonesia yang bersifat job order. Prosedur pengajuan BMDTP kurang selaras dengan asas ease of administration, sehingga menimbulkan cost of taxation yang tinggi. Agar insentif Bea Masuk (BM) bisa lebih efektif dan efisien (tepat waktu, tepat guna dan tepat sasaran), maka disarankan agar pemerintah mengubah kebijakan BMDTP menjadi fasilitas BM sebesar 0\% (tarif preferensi) disertai dengan pengawasan yang baik namun efesien dari pemerintah. Fasilitas BM $0 \%$ hanya diberikan atas impor komponen yang belum diproduksi di dalam negeri atau volume produksi dalam negeri belum mencukupi permintaan industri galangan kapal dalam negeri. Kebijakan fasilitas bea masuk ini semestinya didesain pula dengan mempertimbangkan pertumbuhan industri pendukung atau produsen komponen (barang/ bahan) galangan kapal.
\end{abstract}

Kata Kunci:tax policy, tax incentives, shipyard / ship building, cost of taxation.

\section{Pendahuluan}

Menjadi poros maritim dunia merupakan mimpi besar yang saat ini sedang dicoba untuk diwujudkan oleh pemerintah. Sebagai negara kepulauan terbesar di dunia, Indonesia memang memiliki potensi besar menjadi poros maritim dunia, sebuah gagasan strategis yang diwujudkan untuk menjamin konektivitas antar pulau, pengembangan industri perkapalan dan perikanan, perbaikan transportasi laut serta berfokus pada keamanan maritim. Sebagai negara kepulauan terbesar di dunia, Indonesia memiliki geografis sangat strategis karena dilewati oleh satu Sea Lane of Communication (SLoC), yaitu Selat Malaka yang merupakan peringkat pertama dalam jalur pelayaran kontainer global. Indonesia juga memiliki akses langsung kepada enam wilayah yang mempunyai potensi kelautan dan perikanan yang cukup besar, yaitu: Teluk Bengala; Laut Cina Selatan; Sulu Celebes; Laut-laut Indonesia; Arafura - Gulf Carpentaria; dan Laut Australia Utara (MP3EI).

Dalam beberapa tahun terakhir ini terjadi peningkatan jumlah armada kapal Indonesia, namun, pada kenyataannya jumlah peningkatan tersebut sebagian berasal dari importasi kapal bekas. Penerapan asas cabotage merupakan peluang untuk mengoptimalkan pertumbuhan industri galangan kapal di dalam negeri, namun kebijakan fiskal saat itu yang pro terhadap impor kapal termasuk kapal bekas, menyebabkan pertumbuhan jumlah armada kapal nasional berbanding terbalik dengan Pertumbuhan volume kapal yang dibangun di galangan kapal Indonesia. Hanya kurang dari 20\% dari total $120 \%$ pertumbuhan pada tahun 2005 sd 2014 tersebut berasal dari industri galangan kapal dalam negeri (Iperindo, 2015).

Saat ini terdapat berbagai kendala yang dihadapi oleh industri kapal dalam negeri untuk tumbuh dan berkembang secara berkelanjutan. Salah satunya adalah tingginya persentase komponen atau suku cadang impor yang mencapai lebih kurang $70 \%$ sehingga memperlambat proses produksi sekaligus meningkatkan biaya produksi secara signifikan (Iperindo, 2015).Biaya produksi kapal baru menjadi semakin besar karena terdapat sejumlah pungutan negara atas impor komponen suku cadang kapal pada saat ini yang antara lain meliputi PPh Pasal 22, PPN Impor dan Bea Masuk dengan persentase berkisar antara 17,5\% $32,5 \%$, jauh lebih besar apabila dibandingkan dengan persentase pungutan negara atas impor kapal yang hanya berkisar antara 12,5\%-17,5\%. Disparitas tax treatment atas impor kapal, dan impor komponen kapal untuk produksi kapal dalam negeri dapat dilihat dalam Tabel 1.

\footnotetext{
* Corresponding author. Tel.: +62-21-78849050; fax: +62-21-78849050

E-mail address:haula.rosdiana2013@gmail.com, h.rosdiana@ui.ac.id
} 
Tabel 1. Struktur Biaya dan Pungutan Negaraatas Pembelian Kapal dan Produksi Kapal Baru

\begin{tabular}{|c|c|c|c|c|}
\hline Pemungutan/Biaya & $\begin{array}{l}\text { Pembelian } \\
\text { kapal impor }\end{array}$ & $\begin{array}{l}\text { Produksi kapal } \\
\text { baru domestik }\end{array}$ & $\begin{array}{l}\text { Produksi kapal } \\
\text { di KEK/FTZ }\end{array}$ & Keterangan \\
\hline $\left.\mathrm{PPN}^{*}\right)$ & $10 \%$ & $10 \%$ & $0 \%$ & $\begin{array}{l}\text { Pembebasan di Batam PP } \\
\text { No.10/2012 }\end{array}$ \\
\hline $\begin{array}{l}\text { Bea Masuk: } \\
\text { Kapal } \\
\text { Komponen Kapal }\end{array}$ & $0 \%$ & $5 \%-15 \%$ & $\begin{array}{l}0 \% \\
0 \% \\
\end{array}$ & $\begin{array}{l}\text { Pembebasan di Batam PP } \\
\text { No.10/2012 }\end{array}$ \\
\hline PPh Pasal 22 impor & $2,5 \%-7,5 \%$ & $2,5 \%-7,5 \%$ & $0 \%$ & $\begin{array}{l}\text { Pembebasan di Batam PP } \\
\text { No.10/2012 }\end{array}$ \\
\hline $\begin{array}{l}\text { Pengadaan Mesin dan } \\
\text { Konstruksi Badan Kapal }\end{array}$ & & & & $\begin{array}{l}50 \%-70 \% \text { dari total harga } \\
\text { kapal }\end{array}$ \\
\hline Jasa Konstruksi Kapal & & & & $\begin{array}{l}10 \%-20 \% \text { dari total biaya } \\
\text { konstruksi badan kapal }\end{array}$ \\
\hline Total Pungutan Negara & $12,5 \%-17,5 \%$ & $17,5 \%-32,5 \%$ & $0 \%$ & \\
\hline
\end{tabular}

Tabel 1 menunjukkan bahwa terdapat beberapa variasi struktur pungutan negara yang menyebabkan terjadinya perbedaan level playing field: (1) perbedaan level playing field antara industri galangan kapal dan industri pelayaran dalam aktivitas impor; (2) perbedaan level playing field antara industri galangan kapal di dalam dan di luar Kawasan Ekonomi Khusus (KEK)/Free Trade Zone (FTZ). Perbedaan ini timbul karena terdapat perbedaan kebijakan yang diberikan oleh pemerintah untuk industri pelayaran dalam melakukan importasi kapal jadi dan komponen atau suku cadang yang dilakukan oleh industri galangan.

Industri galangan kapal saat ini memiliki level playing field yang berbeda dalam menjalankan bisnisnya baik dengan industri pelayaran, industri galangan kapal di luar negeri maupun sesama industri galangan kapal yang berada di luar maupun dalam Kawasan Ekonomi Khusus (KEK/FTZ). Industri galangan kapal di luar KEK/FTZ terpaksa menanggung beban pungutan negara yang lebih besar apabila dibandingkan dengan industri sejenis yang berlokasi dalam KEK/FTZ. Meskipun hal ini merupakan konsekuensi dari kebijakan insentif pajak yang diberikan oleh pemerintah untuk mendorong pertumbuhan ekonomi dan industri di KEK/FTZ, namun secara makro justu dapat menciptakan kompetisi yang tidak berimbang. Pengusaha galangan kapal di luar KEK/FTZ sulit bersaing baik dalam tender yang dilakukan pemerintah ataupun di tender bukan oleh pemerintah, karena biaya produksinya lebih tinggi akibat adanya beban pungutan negara dari sektor perpajakan -khususnya Pajak-pajak Dalam Rangka Impor (PDRI).

\section{Akar Masalah 1 (Policy Content Analysis) : Mengapa Insentif Pajak Belum Menjadi Pull Factor untuk Memajukan Industri Galangan Kapal?}

Kebijakan PDRI atas industri galangan kapal tampak belum dirumuskan secara komprehensif, imparsial dan holistik dengan mangacu pada nature of business galangan kapal. Sebagai salah satu faktor pengungkit, industri perkapalan memiliki peran yang sangat strategis dalam mewujudkan Indonesia sebagai poros maritim dunia. Galangan kapal (shipyard) merupakan industri yang bertujuan untuk menghasilkan produk berupa kapal (ship), bangunan lepas pantai (offshore), bangunan terapung (floating plane), dan lain-lain untuk kebutuhan pelanggan (owner, perusahan, pemerintah). Sebagian besar produksi dilakukan berdasarkan spesifikasi yang dipersyaratkan oleh pemesan atau pembeli [1]. Galangan kapal (shipyard) adalah sebuah tempat yang dirancang untuk membuat dan memperbaiki kapal (ship repair). Pada umumnya, industri galangan kapal mempunyai dua bisnis utama yaitu pembuatan kapal baru (new build) dan jasa reparasi (repair and docking).

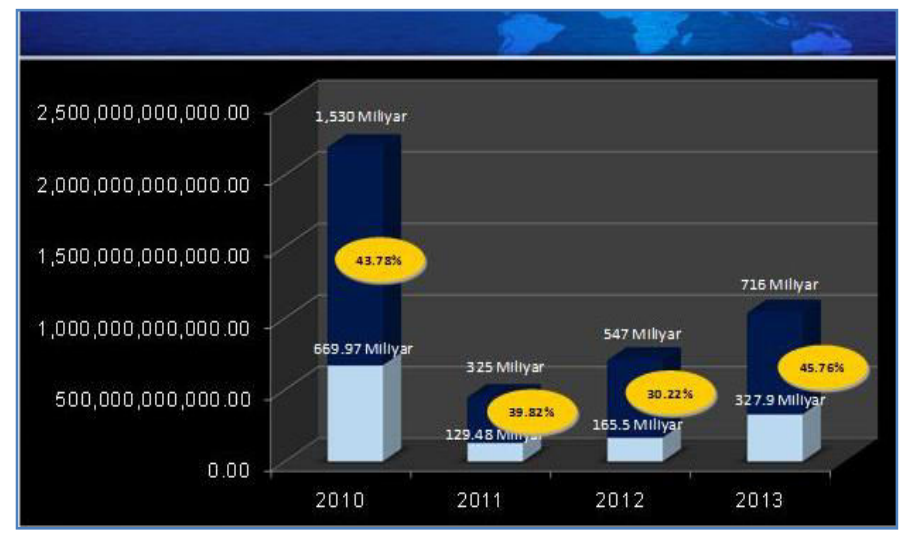

Gambar 1. Penyerapan Pagu BMDTP 2010-2013

Sumber: Direktorat Jenderal Bea dan Cukai, Kementerian Keuangan 
Kapal yang diproduksi bervariasi mulai dari kapal perang, kapal patroli, kapal ferry dan penumpang, kapal kargo, bahkan jenis kapal lainnya. Dengan demikian, maka model bisnis industri galangan kapal saat ini lebih condong pada job order dan bukan mass production. Karena itu, kebijakan Bea Masuk Ditanggung Pemerintah menjadi kurang sesuai dengan model bisnis job order yang lebih condong dengan sistem just in time, sementara BMDTP justru mengacu kepada sistem anggaran dalam APBN. Ketidakcocokan kedua sistem ini dapat menjelaskan mengapa pagu anggaran BMDTP terserap relatif rendah sebagaimana ditunjukkan dalam Gambar 1.

\section{Akar Masalah 2 (Policy Context Analysis) : Mengapa Kebijakan BMDTP justru menciptakan Costs of Taxation yang Relatif Tinggi ?}

Prosedur pengajuan BMDTP justru menciptakan cost of taxation yang tinggi baik material (direct money cost) maupun non material (time cost dan psychological cost). Hal ini terjadi bukan saja karena prosedurnya yang tidak sederhana, proses pencairan yang relatif memakan waktu, namun juga implikasi paska penerimaan BMDTP.

Dalam tataran praktis, ketika pelaku usaha galangan kapal melakukan importasi barang dan bahan baku untuk pembuatan kapal baru dan perbaikan kapal, pada umumnya volume impor akan sangat besar dalam waktu yang bersamaan.Hal demikian dilakukan untuk menekan biaya pengiriman. Ketika kegiatan importasi telah dilakukan, sementara kepastian fasilitas BMDTP belum dapat digunakan, maka perusahaan berpotensi harus membayar bea masuk atau berpotensi membayar demmurage (pengenaan biaya tambahan progresif atas kelebihan waktu dalam pengiriman barang) jika harus menunggu realisasi fasilitas BMDTP. Selain itu, dalam pelaksanaannya fasilitas BMDTP tidak menerapkan sistem restitusi terhadap bea masuk barang yang terlanjur diimpor sehingga ketika bea masuk telah dibayarkan diawal setelah penerbitan Surat Keputusan BMDTP, fasilitas tidak dapat dimanfaatkan.

Kesalahan teknis yang sering terjadi ketika pengajuan RIB terutama mengenai klasifikasi barang (pos tariff bea masuk) yang akan diberikan fasilitas. Dalam tataran praktis, dibutuhkan waktu untuk berkoordinasi antara Ditjen IUBTT Kementerian Perindustrian dengan asosiasi galangan kapal untuk menentukan jenis mesin atau komponen yang belum diproduksi di Indonesia, atau telah diproduksi di Indonesia namun belum memenuhi standard atau jumlahnya belum memenuhi kebutuhan galangan kapal Indonesia.

\section{Konstruksi Ulang Kebijakan Insentif Bea Masuk Untuk Meningkatkan Produktivitas Industri Galangan Kapal di Indonesia}

\subsection{Memilih Kebijakan yang Lebih Sesuai Dengan Model Bisnis Industri Galangan Kapal}

Sebagaimana telah dijelaskan dalam analisis sebelumnya, kebijakan BMDTP kurang sesuai dengan model bisnis industri galangan kapal sehingga efektivitas kebijakan ini menjadi relatif kurang berhasil. Padahal kebijakan BMDTP sebenarnya ditujukan sebagai bentuk dukungan pemerintah terhadap industri galangan kapal. Agar tujuan pemerintah ini dapat diimplementasikan dengan baik dan mendapatkan manfaat seperti yang diharapkan, maka pemerintah perlu melakukan konstruksi ulang atas kebijakan insentif BM yang lebih sesuai dengan model bisnis industri galangan kapal di Indonesia.

Secara international best practice, kebijakan preferential tariff misalnya tariff $0 \%$ bisa menjadi alternatif kebijakan yang lebih sesuai dengan industri galangan kapal, dengan memperhatikan beberapa kelebihannya sebagaimana dapat dilihat dalam Tabel di bawah ini:

Tabel 2. Perbandingan Kebijakan Pembebasan BM 0\% dan Kebijakan BMDTP

\begin{tabular}{|c|c|c|}
\hline Deskripsi & $\begin{array}{l}\text { Kebijakan Tarif Preferensi } \\
\text { (Misalnya Bea Masuk 0\%) }\end{array}$ & Kebijakan BMDTP \\
\hline Tujuan & $\begin{array}{l}\text { Berorientasi pada kemudahan perdagangan } \\
\text { internasional dan kemudahan arus barang } \\
\text { untuk tujuan kegiatan ekonomi global }\end{array}$ & $\begin{array}{l}\text { Kebijakan pemerintah dalam mengalokasikan } \\
\text { anggaran dalam rangka menanggung beban } \\
\text { Bea Masuk atas Pajak Dalam Rangka Impor } \\
\text { (PDRI). }\end{array}$ \\
\hline Fokus & $\begin{array}{l}\text { Pengenaan tariff } 0 \% \text { dalam BTBMI merupakan } \\
\text { bentuk pembebasan mutlak (absolut) tanpa } \\
\text { syarat apapun dan berlaku sepanjang } \\
\text { memenuhi ketentuan yang berlaku }\end{array}$ & $\begin{array}{l}\text { BMDTP ditujukan untuk barang dan bahan } \\
\text { dengan kriteria tertentu terkait kegiatan industri }\end{array}$ \\
\hline Jenis & Tax Incentives & Spending Policy (Tax Expenditure) \\
\hline Enforcement Cost & Sedang - Tinggi & Sedang - Tinggi \\
\hline Compliance Cost & $\begin{array}{l}\text { Relatif rendah karena tahapan yang dilalui } \\
\text { dalam pelaksanaan kebijakan lebih sederhana }\end{array}$ & $\begin{array}{l}\text { Relatif tinggi karena tahapan implementasi } \\
\text { kebijakan yang panjang dan melalui berbagai } \\
\text { instansi. }\end{array}$ \\
\hline Efektivitas & Relatif tinggi & Relatif rendah \\
\hline
\end{tabular}




\subsection{Dampak Makro Kebijakan Pembebasan Bea Masuk 0\% atas Impor Komponen Kapal}

Ketika pemerintah memberikan insentif fiskal, tentu hal tersebut akan menyebabkan timbulnya potential loss bagi pemerimaan negara. Namun demikian, perlu mempertimbangkan dampak positif dari pelaksanaan kebijakan insentif tersebut. Meskipun pemerintah akan mengalami potensi penurunan penerimaan dari Bea Masuk atas importasi komponen kapal, namun diharapkan insentif yang diberikan tersebut mampu menghasilkan dampak multiplier bagi kegiatan ekonomi lain-nya.

Industri galangan kapal merupakan jenis industri yang memiliki mata rantai ekonomi yang panjang sehingga pertumbuhan industri galangan kapal tidak hanya mempengaruhi industri ini semata, namun akan mempengaruhi pertumbuhan industri penunjang. Selain itu, pertumbuhan industri ini serta industri penunjang pada akhirnya akan mampu meningkatkan penyerapan tenaga kerja, sebagaimana dideskripsikan dalam Gambar di bawah ini

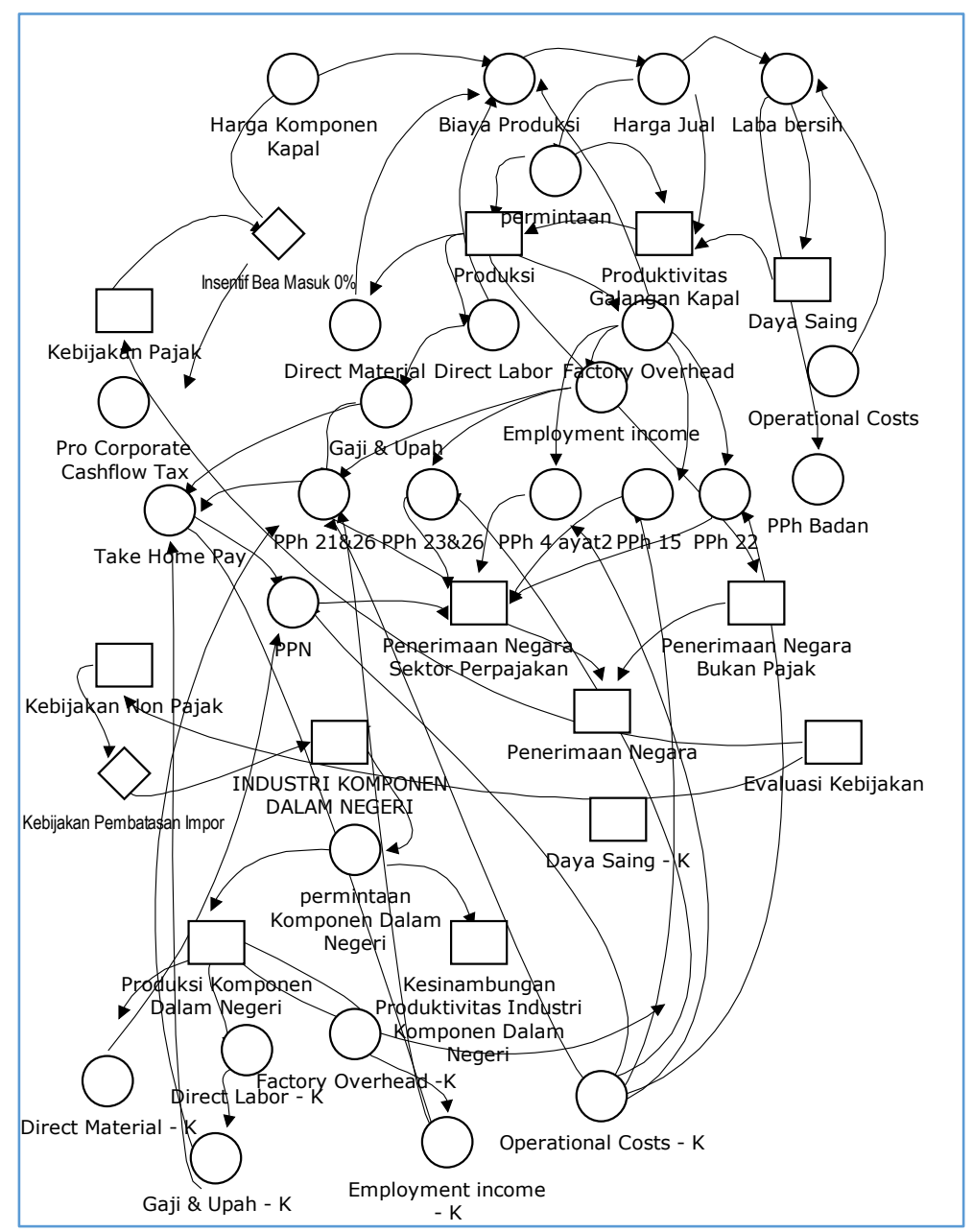

Gambar 2. Dampak Ekonomi Pembebasan Bea Masuk

Causal loopdi atas mendeskripsikan jika pemerintah merekonstruksi ulang kebijakan Bea masuk dari BMDTP menjadi Pembebasan BM 0\%, maka insentif pembebasan Bea Masuk akan memberikan pengaruh langsung kepada penurunan biaya produksi secara umum karena berkurangnya komponen pajak yang merupakan faktor pembentuk biaya produksi. Biaya produksi yang lebih murah akan mendorong harga jual yang lebih murah. Selain itu, insentif pembebasan Bea Masuk juga mempengaruhi cash flow perusahaan dalam menjalankan kegiatan produksi. Dengan harga jual yang lebih murah, akan mampu meningkatkan produktivitas, daya saing yang pada akhirnya akan mampu meningkatkan laba. Dengan demikian peningkatan laba yang sustain akan mampu mendorong pertumbuhan industri.

Produktivitas yang semakin baik pada dasarnya membutuhkan tenaga kerja yang kuantitas dan kualitasnya meningkat, supply bahan baku utama (direct material) dan biaya overhead. Peningkatan produktivitas akan mendorong peningkatan penyerapan tenaga kerja (direct labor) serta komponen dan material (direct material) untuk kegitan produksi serta faktor-faktor penunjang lainnya (factory overhead). Pada akhirnya pemerintahpun akan memperoleh penerimaan pajak berupa PPh Badan atas industri galangan kapal yang semakin berkembang dan menguasai pasar terutama pasar industri dalam negeri, PPh Pasal 21 dari tenaga kerja yang semakin meningkat jumlahnya, serta PPh Pasal 23/26 dari setiap transaksi khususnya jasa yang berhubungan 
dengan kegitan shipbuilding/repaire. Selain itu, pemerintah juga akan memperoleh PPN dari pembelian barang kena pajak yang dibutuhkan oleh sektor galangan kapal.

Secara khusus, pembebasan Bea Masuk atas importasi komponen kapal diharapkan mampu meningkatkan competitiveness dan produktivitas galangan kapal. Dampak positif atau multiplier dari kebijakan pembebasan bea masuk bagi industri galangan kapal dapat diilustrasikan sebagai berikut:

Tabel 3.Ilustrasi Dampak Insentif Bea Masuk bagi Industri Galangan Kapal

\begin{tabular}{|c|c|c|c|c|c|c|c|c|c|c|c|c|}
\hline \multirow{4}{*}{ Komponen asal } & \multirow{4}{*}{$\%$} & \multirow{4}{*}{ Nilai } & \multicolumn{8}{|c|}{ Sebelum Penghapusan Bea masuk } & \multicolumn{2}{|c|}{ asumsi } \\
\hline & & & \multicolumn{8}{|c|}{ Pendapatan Pemerintah } & \multirow{7}{*}{\multicolumn{2}{|c|}{$\begin{array}{c}\text { Pembebasan Bea masuk } \\
\text { menimbulkan kesempatan } \\
\text { untuk meningkatkan } \\
\text { produktivitas dalam hal } \\
\text { peningkatan volume } \\
\text { produksi sebesar } 20 \% \text { dan } \\
\text { peningkatan lokal content } \\
\text { sebesar } 10 \%\end{array}$}} \\
\hline & & & PPN & \begin{tabular}{|c|c|} 
PPh 22 & $P$ \\
lokal & $i$ \\
\end{tabular} & \multirow{2}{*}{\begin{tabular}{|c|}
$\begin{array}{c}\text { PPh 22 } \\
\text { impor }\end{array}$ \\
$7,5 \%$ \\
\end{tabular}} & \multirow{2}{*}{ 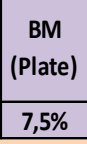 } & $\begin{array}{c}\text { BM } \\
\text { (komp } \\
\text { utama) }\end{array}$ & \multirow{2}{*}{\begin{tabular}{|c|c}
$\begin{array}{c}\text { BM } \\
\text { (Komp) }\end{array}$ \\
$10,0 \%$ \\
\end{tabular}} & \multirow[t]{2}{*}{ Total } & \multirow[t]{2}{*}{$\begin{array}{c}\text { Quantity } \\
\text { sales } \\
\text { (Unit) }\end{array}$} & & \\
\hline & & & $10,0 \%$ & $0,3 \%$ & & & $7,5 \%$ & & & & & \\
\hline Lokal & $35 \%$ & & & & & & & & & \multirow[t]{4}{*}{500} & & \\
\hline Plat & $30 \%$ & 151 & 15 & 0 & - & & - & & 16 & & & \\
\hline Komponen lainnya & $5 \%$ & 27 & 3 & - & - & 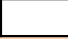 & - & & 3 & & & \\
\hline Impor & $65 \%$ & & & & & & & & & & & \\
\hline Plat & $7 \%$ & 33 & 3 & - & 2 & 2 & 2 & - & 8 & & \multirow{4}{*}{\multicolumn{2}{|c|}{$\begin{array}{c}\text { Kenaikan content local } \\
10 \% \\
\end{array}$}} \\
\hline Komponen utama & $36 \%$ & 181 & 18 & 1 & 14 & & 14 & - & 46 & \multirow[b]{2}{*}{ Rupiah } & & \\
\hline \multirow[t]{2}{*}{ Komponen lainnya } & $59 \%$ & 296 & 30 & - & 22 & & - & 30 & 81 & & & \\
\hline & & 687 & 69 & 1 & 38 & $=$ & 14 & 30 & 154 & 76.777 & & \\
\hline \multirow{4}{*}{ Komponen asal } & & \multirow{4}{*}{$\%$} & \multirow{4}{*}{ Nilai } & \multicolumn{9}{|c|}{ Setelah Penghapusan Bea Masuk } \\
\hline & & & & \multicolumn{9}{|c|}{ Pendapatan Pemerintah } \\
\hline & & & & PPN & \multicolumn{2}{|c|}{$\begin{array}{l}\text { PPh } 22 \\
\text { lokal }\end{array}$} & $\begin{array}{l}\text { PPh } 22 \\
\text { impor }\end{array}$ & $\begin{array}{c}\text { Bea } \\
\text { masuk } \\
\text { (Plate) }\end{array}$ & $\begin{array}{c}\text { BM } \\
\text { (komp } \\
\text { utama) }\end{array}$ & \begin{tabular}{c|c} 
Bea \\
masuk \\
(Komp)
\end{tabular} & Total & \multirow[t]{2}{*}{$\begin{array}{c}\text { Quantity } \\
\text { sales } \\
\text { (Unit) }\end{array}$} \\
\hline & & & & $10,0 \%$ & 0,3 & & $7,5 \%$ & $0,0 \%$ & $0,0 \%$ & $0,0 \%$ & & \\
\hline \multicolumn{2}{|l|}{ Lokal } & $45 \%$ & & & & & & & & & & 625 \\
\hline \multicolumn{2}{|l|}{ Plat } & $38 \%$ & 194 & 19 & & 1 & - & - & & - & 20 & \\
\hline \multicolumn{2}{|c|}{ Komponen lainnya } & $7 \%$ & 34 & 3 & 3 & - & - & - & & - & 3 & \\
\hline \multicolumn{2}{|l|}{ Impor } & $55 \%$ & & & & & & & & & & \\
\hline \multicolumn{2}{|l|}{ Plat } & $6 \%$ & 28 & 3 & 3 & - & 2 & - & - & - & 5 & \\
\hline \multicolumn{2}{|c|}{ Komponen utama } & $30 \%$ & 153 & 15 & & 0 & 11 & - & - & - & 27 & \\
\hline \multirow{2}{*}{\multicolumn{2}{|c|}{ Komponen lainnya }} & $50 \%$ & 250 & 25 & & - & 19 & - & - & - & 44 & Rupiah \\
\hline & & & 659 & 66 & & 1 & 32 & - & & - & 99 & 62.062 \\
\hline
\end{tabular}

Sumber: Data diolah peneliti

Dari ilustrasi diatas, dapat disimpulkan bahwa terjadi potential loss (revenue forgone) berupa penurunan penerimaan pemerintah dari sektor pungutan pajak sebesar 19,2\% namun kebijakan pembebasan Bea Masuk tersebut mampu meningkatkan kesempatan produksi atau peningkatan produktivitas, yaitu peningkatan volume produksi sebesar 20\% serta peningkatan pengunakan local content sebesar 10\%. Peningkatan produksi yang berkelanjutan diharapkan mampu menjadikan industri galangan pasar menjadi supplier utama bagi industri pelayaran dalam negeri. Selain itu, jika menganalisis dengan seksama, dampak positif pemberian Bea Masuk bagi peningkatan penerimaan industri galangan kapal serta potential revenue yang akan diperoleh pemerintah dari PPh Badan sektor galangan kapal dapat digambarkan sebagai berikut:

Tabel 4.Ilustrasi Dampak Insentif Bea Masuk bagi Peningkatan Laba Industri Galangan Kapal serta Penerimaan Pemerintah dari PPh Badan Industri Galangan Kapal

\begin{tabular}{|c|c|c|c|c|c|c|c|c|c|c|c|c|}
\hline \multirow{3}{*}{ Struktur Laba Rugi } & \multicolumn{6}{|c|}{ Sebelum Pembebasan Biaya Masuk (BM) } & \multicolumn{6}{|c|}{ Setelah Pembebasan Biaya Masuk (BM) } \\
\hline & \multirow[t]{2}{*}{$\%$} & \multirow[t]{2}{*}{ Quantity } & \multirow[t]{2}{*}{ Rp per unit } & \multirow{2}{*}{\begin{tabular}{|c|}
$\begin{array}{c}\text { BM } \\
\text { (Plate) }\end{array}$ \\
$7,5 \%$ \\
\end{tabular}} & \multirow{2}{*}{\begin{tabular}{|c|}
$\begin{array}{c}\text { BM } \\
\text { (Komp) }\end{array}$ \\
$15,0 \%$ \\
\end{tabular}} & \multirow[t]{2}{*}{ Nilai Rp } & \multirow[t]{2}{*}{$\%$} & \multirow[t]{2}{*}{ Quantity } & \multirow{2}{*}{ Rp per unit } & \multirow{2}{*}{\begin{tabular}{|c|c}
$\begin{array}{c}\text { BM } \\
\text { (Plate) }\end{array}$ \\
$0,0 \%$ \\
\end{tabular}} & \multirow{2}{*}{\begin{tabular}{|c|}
$\begin{array}{c}\text { BM } \\
\text { (Komp) }\end{array}$ \\
$0,0 \%$ \\
\end{tabular}} & \multirow[t]{2}{*}{ Nilai Rp } \\
\hline & & & & & & & & & & & & \\
\hline Penjualan & $100 \%$ & 500 & 1.000 & - & - & 500.000 & $100 \%$ & 625 & 1.000 & - & - & 625.000 \\
\hline \multicolumn{13}{|c|}{ Harga Pokok Penjualan (COGS) } \\
\hline \multicolumn{13}{|l|}{ Komponen: } \\
\hline \multicolumn{13}{|l|}{ Lokal: } \\
\hline Plat & $23 \%$ & 500 & 193 & - & - & 96.688 & $29 \%$ & 625 & 249 & - & - & 155.391 \\
\hline Komponen lainnya & $4 \%$ & 500 & 34 & - & - & 17.063 & $5 \%$ & 625 & 44 & - & - & 27.422 \\
\hline \multicolumn{13}{|l|}{ Impor: } \\
\hline Plat & $5 \%$ & 500 & 42 & 3 & - & 22.709 & $4 \%$ & 625 & 36 & - & - & 22.344 \\
\hline Komponen utama & $36 \%$ & 500 & 232 & 17 & - & 124.902 & $23 \%$ & 625 & 197 & - & - & 122.891 \\
\hline Komponen lainnya & $17 \%$ & 500 & 148 & - & 22 & 85.028 & $15 \%$ & 625 & 125 & - & - & 78.203 \\
\hline Tenaga Kerja & $15 \%$ & 500 & 128 & - & - & 63.750 & $15 \%$ & 625 & 128 & - & - & 79.688 \\
\hline Factory overhead & $9 \%$ & 500 & 73 & - & - & 36.250 & $9 \%$ & 625 & 73 & - & - & 45.313 \\
\hline \multicolumn{6}{|c|}{ Total COGS } & 446.389 & \multicolumn{5}{|c|}{ Total COGS } & 531.250 \\
\hline \multicolumn{6}{|c|}{ Marjin keuntungan } & 53.611 & \multicolumn{5}{|c|}{ Marjin keuntungan } & 93.750 \\
\hline \multicolumn{6}{|c|}{ pajak Penghasilan $25 \%$} & 13.403 & \multicolumn{5}{|c|}{ pajak Penghasilan 25\% } & 23.438 \\
\hline
\end{tabular}

Sumber: Data diolah peneliti 
Dari ilustrasi diatas dapat disimpulkan bahwa kenaikan produksi 125 unit kapal dan insentif Bea Masuk dapat meningkatkan laba perusahaan sebesar Rp. 40.139 bagi industri galangan kapal. Peningkatan laba tersebut akan berdampak bagi peningkatan penerimaan pemerintah yang berasal dari PPh Badan sebesar Rp. 23.438 atau sebesar 74,9\%.

Kebijakan insentif merupakan bentuk dari fungsi pajak sebagai instrumen economic, social and political engineering. Hal ini juga berarti bahwa kebijakan insentif bersifat sementara hingga tujuan dari pemberian insentif tercapai. Pemberian insentif Bea Masuk yang merupakan bagian dari instrumen social engineering juga sudah selayaknya diterapkan sesuai dengan maksud dan tujuan serta dilakukan pengawasan terhadap pelaksanaannya. Dalam konteks pemberian insentif Bea Masuk 0\%, perlu ditekankan bahwa meskipun industri galangan kapal diberikan keleluasaan untuk melakukan importasi komponen, namun optimalisasi komponen produksi dalam negeri merupakan pilihan utama.

Pilihan untuk melakukan importasi harus diselaraskan dengan keadaan dan kapasitas industri komponen dalam negeri. Dalam tataran praktis, hal ini berarti bahwa importasi komponen dilakukan apabila industri komponen dalam negeri belum atau tidak mampu memproduksi komponen yang dibutuhkan oleh industri galangan kapal atau kuantitas yang diproduksi di dalam negeri belum mampu memenuhi permintaan industri galangan kapal. Bahkan diperlukan suatu kebijakan yang bersifat obligatory untuk mendorong industri galangan kapal dalam mengoptimalkan penggunaan komponen produksi dalam negeri sebelum diberikan fasilitas impor. Disisi lain, kebijakan ini juga diharapkan mampu mempercepat pertumbuhan industri komponen dalam negeri yang memenuhi standar produksi komponen galangan kapal.

Ketika pemerintah telah memberikan fasilitas insentif Bea Masuk 0\%, pelaksanaan kebijakan ini juga perlu diawasi dengan baik namun dengan pelaksanaan administrasi yang sederhana dan efisien. Hal ini diharapkan bahwa insentif benar-benar diterima dan dimanfaatkan oleh pihak yang menjadi target tujuan pembuatan kebijakan. Dalam tataran praktis, pembuatan angka pengenal produsen dalam kegiatan importasi menjadi sangat vital dalam kegiatan pengadministrasian. Selain itu, pembuatan klasifikasi komponen yang menjadi bahan pembuatan kapal juga perlu menjadi perhatian pemerintah agar fasilitas ini tidak disalahgunakan oleh industri lain diluar industri yang menjadi target pemerintah. Selain itu, evaluasi berkala atas kebijakan insentif ini juga perlu dilakukan oleh pemerintah misalnya dalam setiap dalam kurun waktu 3 tahun dimana pada kurun waktu tersebut galangan kapal diharapkan sudah mampu memiliki daya saing dengan mempertimbangkan karakteristik industrinya.

\section{Simpulan}

Pemerintah sudah mulai menunjukkan dukungan terhadap industri galangan kapal terutama mengingat bahwa pemerintah memiliki cita-cita untuk menjadikan Indonesia sebagai poros maritim dunia melalui fasilitas bea masuk, yaitu Bea Masuk ditanggung pemerintah (BMDTP) terhadap importasi komponen untuk industri galangan kapal. Fasilitas ini diberikan berdasarkan basis tahun anggaran yang diatur dalam APBN. Impor komponen kapal di Indonesia tergolong cukup tinggi karena spesifikasi dan volume yang dibutuhkan belum mampu diproduksi di dalam negeri. Namun, dalam tataran praktis, fasilitas ini belum dimanfaatkan secara optimal oleh industri galangan kapal yang disebabkan oleh berbagai faktor seperti lamanya pembuatan regulasi teknis serta kerumitan administrasi.

Jenis insentif ini juga dianggap kurang sesuai dengan karakteristik industri galangan kapal yang padat modal dan padat karya sehingga insentif ini kurang menarik. Selain pilihan fasilitas BMDTP terdapat alternatif lain, yaitu penurunan tariff bea masuk hingga $0 \%$ melalui pengaturan tarif pos bea masuk dalam BTBMI. Namun demikian kebijakan ini semestinya didesain dengan baik agar tepat sasaran dan mampu mendorong pertumbuhan industri galangan kapal dalam negeri dan industri pendukungnya.

\section{Rekomendasi}

Berdasarkan kesimpulan yang telah dilakukan, maka beberapa saran yang perlu menjadi perhatian berbagai pihak sebagai berikut:

1. Pemerintah sebaiknya mempertimbangkan untuk mengubah bentuk pemberian fasilitas BMDTP menjadi pembebasan bea masuk melalui penurunan tariff $0 \%$ melalui pos tariff BTBMI Indonesia. Perubahan kebijakan ini didasarkan kepada pertimbangan kemudahan administrasi dan optimalisasi manfaat dari insentif yang disediakan pemerintah sehingga pelaku usaha benar-benar dapat merasakan manfaat dari pemberian insentif tersebut, bukan semata-mata menumbuhkan pertambahan rantai penjualan komponen. Diharapkan dengan semakin berkembangnya industri ini, maka akan mampu mendorong sektor maritime secara keseluruhan serta menurunkan biaya logistik. Kehilangan potensi bea masuk pada akhirnya akan direcapture melalui peningkatan penyerapan tenaga kerja serta manfaat ekonomi lainnya dari peningkatan produktivitas industri ini.

2. Pemberian fasilitas Bea Masuk 0\% harus diikuti dengan pengawasan yang baik namun efesien dari pemerintah. Importasi diberikan atas pembelian komponen yang belum diproduksi di dalam negeri atau volume produksi dalam negeri belum mencukupi permintaan industri galangan kapal dalam negeri. Selain itu, dari sisi administrasi, pemerintah juga perlu melakukan klasifikasi atas jenis komponen yang akan diberikan pembebasan impor dan angka pengenal impor produsen bagi pelaku usaha galangan kapal yang akan melakukan impor.

3. Kebijakan fasilitas bea masuk ini semestinya didesain pula dengan mempertimbangkan pertumbuhan industri pendukung atau produsen komponen (barang/ bahan) galangan kapal. Dengan demikian, kebijakan pembebasan bea masuk atas komponen (barang/ bahan) kapal sebaiknya memperhatikan hal-hal sebagai berikut: 
a. Keterserapan komponen produksi dalam negeri. Apabila hasil produksi komponen dalam negeri belum sepenuhnya terserap, maka fasilitas pembebasan bea masuk ini tidak dapat diberikan.

b. Fasilitas bea masuk $0 \%$ hanya dapat diberikan untuk komponen yang memang belum dapat diproduksi di dalam negeri.

c. Kebijakan insentif bea masuk 0\% semestinya dievaluasi secara berkala minimal 3 (tiga) tahun sekali. Dalam kurun waktu tersebut, apabila komponen tertentu telah mampu diproduksi secara komersial di dalam negeri maka kebijakan insentif bea masuk $0 \%$ tidak dapat diberikan.

\section{Acknowledgements}

Riset ini merupakan bagian dari riset kami yang berjudul : Menuju Poros Maritim Dunia : Kebijakan Fiskal untuk Mendorong Industri Galangan Kapal dari Perspektif Quantiple Helix yang didanai oleh DPRM UI melalui skema PUPT 2016. Untuk itu kami mengucapkan terima kasih atas kepercayaan DRPM UI. Terselenggaranya riset ini juga tidak akan terlaksana tanpa bantuan dari Iperindo, Kementerian Perindustrian, Kementerian Koordinator Bidang Perekonomian, Badan Kebijakan Fiskal dan Direktorat Jenderal Pajak. Untuk itu, kami menghaturkan terima kasih kepada semua pihak yang telah berkontribusi dalam pelaksaaan penelitian ini.

\section{References}

[1] Munawar, Estimasi Kebutuhan Material Utama untuk Menunjang Industri Perkapalan Indonesia. Surabaya: Teknik Perkapalan Institut Teknologi Sepuluh November, 2009.

\section{Use the "Insert Citation" button to add citations to this document.}

[2] Dimyati Ahmad, (2011), Teknis Kepabeanan, Pusdiklat Bea Cukai, Kementerian Keuangan RI.

[3] Dye Thomas R., (2002), Undertanding Public Policy, 10th edition, United States: Pearson Education..

[4] Ernst and Young, (2013), Shipping Industri Almanac

[5] Government of India, Ministry of Shipping, Road Transport \& Highways, (2013), Report of Working Group for Shipbuilding and Ship-repair Industri for the Eleven Year Plan.

[6] Irianto Edi Slamet, (2012), Kebijakan Fiskal dan Pengelolaan Pajak di Indonesia, Jakarta: Aswaja Pressindo.

[7] Khalid Naery, Hasan Elvia (2011), Incentives for the Development of Malaysia Merchant Shipping and Port Sectors.

[8] Kementerian Keuangan RI (2012) Penyusunan Peraturan Menteri Keuangan tentang Penetapan Sistem Klasifikasi Barang dan Pembebanan Tarif Bea Masuk atas Barang Impor.

[9] Lindawati Rita (2015) Menilik Pelaksanaan Fasilitas Bea Masuk Ditanggung Pemerintah Sebagai Salah Satu Kebijakan Fiskal di Bidang Kepabeanan, Pusdiklat Bea Cukai Kementerian Keuangan RI.

[10] Musgrave Richard, Musgrave Peggy, (1984), Public Finance in Theory and Practice, Singapore: Mcgraw-Hill.

[11] Neuman Lawrence, (2003), Social Research Methods: Qualitative and Quantitative Approachers, USA: Pearson Education Inc.

[12] Nugroho Riant, (2011), Public Policy: Dinamika Kebijakan, Analisis Kebijakan, Manajemen Kebijakan, Jakarta: Elex Media Komputindo.

[13] Osborn David, Gaebler Tied, (1999), Mewirausahakan Birokrasi: Mentransformasi Semangat Wirausaha ke dalam Sektor Publik (Reinventing Government), Jakarta: Pustaka Binaman Pressindo

[14] OECD (2015) OECD Economic Surveys Japan,

[15] OECD (2013) Peer Review of Japanese Government Support Measures to the Shipbuilding Sector, Council Working Party on Shipbuilding.

[16] Surono (__ Fasilitas Pabean: Suatu Upaya Pemberian Kemudahan dan Insentif Fiskal bagi Industri dan Perdagangan, Pusdiklat Bea dan Cukai Kementerian Keuangan RI.

[17] Surono (__ _ Kebijakan Pajak Pertambangan Nilai Pada Industri Galangan Kapal Nasional, Pusdiklat Bea dan Cukai Kementerian Keuangan RI.

[18] Purwito M. (2006), Ahli Kepabeanan: Konsep dan Aplikasi, Jakarta: Samudra Ilmu

[19] Thangam K. Muthuchelvi dan Sureshkumar, (2015) Competitiveness of Indian Ship Building Industri, International Journal of Innovative Research \& Development Vol. IV/7.

[20] Rencana Strategis Badan Koordinasi Penanaman Modal 2015-2019

[21] Rosdiana Haula (2008), Rekonstruksi Konsepsi Supply Side Tax Policy, International Journal of Administrative Science and Organization, Vol 15 (1).

[22] (2010), How 'Pro Corporate Cash-Flow Tax' Design May Promote the Development of Telecommunication Industry, International Journal of Administrative Science and Organization Vol.17 (3).

[23] _ Reformulating Policy on Frequency Usage Fees as Non-Tax State Revenue: Urgency and Its Implications Journal of Indonesian Economy and Business., 25 (2).

[24] _ (2004) Tax Cut of Sales Tax on Luxury Goods in Stimulating Investment Growth on Electronics Industry 
(Tax Cut PPnBM sebagai Stimulus Pertumbuhan Investasi Industri Elektronika, International Journal of Administrative Science and Organization., 12. ,(2011), Evaluating Non-Tax Levies for Higher Education, International Journal of Administrative Science and Organization Vol. 18 (2).

[26] (2013), Does State Levies Policy Support Minapolitan Program in Indonesia International, Journal of Administrative Science and Organization 20 (1).

[27] \& \& Irianto, Edi Slamet, (2012), Pengantar Perpajakan : Kebijakan dan Implementasinya di Indonesia . Jakarta: Rajawali Pers.

[28] _ Irianto, Edi Slamet, \& Putranti, Titi M.,(2011), Pajak Pertambahan Nilai : Kebijakan dan Implementasinya di Indonesia. Jakarta: Ghalia Indonesia.

[29] Sandford, Cedric, Godwin, M.R., \& Hardwick, P.J.W., (1989), Administrative and Compliance Costs of Taxation. Fiscal Publications.

[30] Radovic Dragan, (2012), State Regulation as Institutional Presumption of Maritim Development in the World, Montenegrin Journal of Economic, Vol. 8 No. 3

[31] Sudarmo Sudjanadi, (2012) Memberdayakan Kembali Manajemen Pelabuhan di Indonesia, Jakarta: Australian Aid.

[32] UNCTAD, (2000) Tax Incentive and Foreign Direct Investment: A Global Survey,United Nation, 